\title{
De la Peste Antonina a la Peste de Cipriano: Alcances y consecuencias de las pestes globales en el Imperio Romano en el siglo III d.C.
}

\author{
From the Antonine Plague to the Cyprian Plague: Scopes and consequences of global \\ plagues in the Roman Empire in the 3rd century AD.
}

\author{
Andrés Sáez Geoffroy y Joel Parra Díaz ${ }^{2}$
}

'Departamento de Ciencias Sociales. Universidad de La Frontera, Temuco, Chile.

${ }^{2}$ Departamento de Educación. Universidad de La Frontera, Temuco, Chile.

Financiado por Proyecto Fondecyt de Iniciación № 11180219, titulado: "La Pax Antonina: ideología militar, política exterior y gran estrategia del Imperio Romano en el siglo de los Antoninos".

Recibido: 29 de mayo de 2020

\section{Resumen}

El Imperio Romano sufrió entre el siglo II y III dos grandes pestes, la Peste Antonina, de la cual existe bibliografía, y la Peste de Cipriano, que es menos conocida. Como una visión de conjunto, ambas pandemias se asemejan a la crisis que en el 2020 el coronavirus está generando en muchos aspectos de la vida humana. Este artículo se centra en el impacto que la peste de Cipriano tuvo en el contexto de la crisis del siglo III; su mortalidad se estima entre $10-20 \%$ de la población en los lugares afectados y finalmente sus efectos generaron varias de las condiciones necesarias para la transición del mundo antiguo al medieval. Se trata de comprender cómo el ciclo de pestes que va desde el siglo II al siglo III cambió la fisonomía del mundo romano y que lecciones nos entrega la historia 1700 años después.

Palabras clave: Peste Antonina; Peste de Cipriano; fiebre hemorrágica viral; Imperio Romano.

\section{Introducción}

L

a OMS ha definido como pandemia "la propagación mundial de una nueva enfermedad"1. La presencia de brotes infecciosos ha acompañado la vida humana desde sus inicios; cada una de las grandes civilizaciones que ha habitado nuestro planeta se ha visto afectada por una o más pandemias en su cosmovisión era su mundo. Cabría evaluar qué aprendizaje nos entrega la historia de las enfermedades, como ciencia que estudia el pasado, para comprender

\section{Correspondencia a:}

Andrés Sáez Geoffroy

andres.saez@ufrontera.cl
Joel Parra Díaz

joel.parra@ufrontera.cl

\section{Abstract}

Between the 2nd and 3rd centuries the Roman Empire suffered two great plagues, the Antonine Plague, of which there is a bibliography, and the lesser known Plague of Cyprian. As an overview, both pandemics resemble the crisis that in 2020 the Coronavirus is generating in many aspects of human life. This article focuses on the impact that the Cyprian plague had in the context of the crisis of the third century, its mortality is estimated between $10-20 \%$ of the population in the affected places, finally its effects generated several of the necessary conditions for the transition from the ancient to the medieval world. It is about understanding how the cycle of plagues that went from the 2nd century to the 3 rd century changed the appearance of the Roman world and what lessons history gives us 1700 years later.

Keywords: Antonine Plague; Cyprian Plague; viral hemorrhagic fever; Roman Empire.

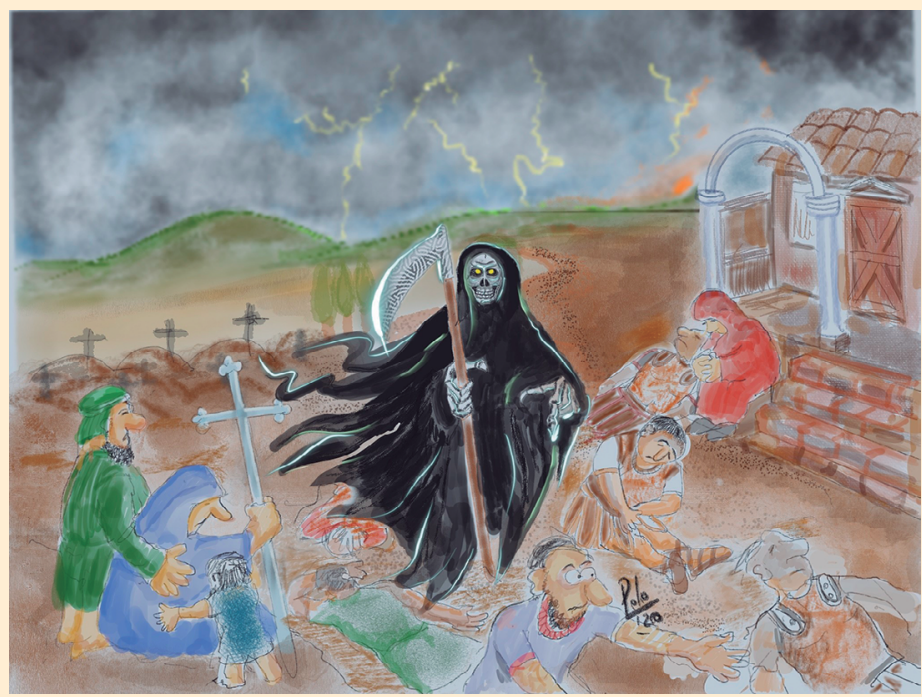


En este contexto de evidente inestabilidad y fragilidad, tal cual como lo podemos observar hoy día en 2020 por la pandemia del COVID-19 en diferentes estados del mundo, surgió una "crisis económica" generalizada, que afectó a todo el Imperio Romano, con manifestaciones evidentes en la baja productividad, escasez de recursos, devaluación monetaria, pérdida de poder adquisitivo, especulación y presión fiscal; efectos que por lo menos se sintieron durante todo el siglo III. Las situaciones políticas y económicas señaladas, evidentemente tuvieron una incidencia social. Aparecieron nuevas tensiones y conflictos que socavaron el antiguo orden romano conocido como el principado. La crisis alcanzó un estado global cuando las costumbres y religiones tradicionales no fueron capaces de dar una respuesta a la crisis, produciendo un vacío moral e ideológico en el que ganaron terreno nuevas corrientes, como las religiones mistéricas orientales y el cristianismo, una cuestión que sería fundamental en la transición del mundo antiguo a la edad media.

En ese contexto de estudio, a mediados del siglo III, ocurrió una nueva peste, la llamada Peste de Cipriano, denominada así por ser descrita por el obispo Cipriano de Cartago, uno de los primeros líderes cristianos. Esta pandemia, al igual que la Peste Antonina medio siglo antes, agravó la situación en que se encontraba el orden político, social, económico y cultural. La historia, como disciplina que estudia el pasado del ser humano, ha obviado en los grandes relatos la relevancia de las enfermedades y las pestes en el establecimiento de nuevas estructuras sociales. En ese marco la Peste de Cipriano ha sido estudiada en mucho menor grado que la Peste Antonina y la Peste de Justiniano, siendo abordada principalmente por K. Harper 5 .

los que se visualizó una unidad cultural que ticamente abarcaba toda la cuenca del Mediterráneo. Estaba consolidado el proceso de romanización en los pueblos conquistados, la vida en las ciudades presentaba excelentes posibilidades gracias a la disponibilidad de baños, acueductos y otros servicios, y se gozaba de lo que se conoce como la pax romana, situación que algunos historiadores la enuncian como un símil de nuestra actual globalización ${ }^{4}$.

La historiografía permite señalar que, tras la muerte de Marco Aurelio, el desarrollo de la autocracia de Cómodo y la modificación de las estructuras de poder que se observaron bajo el gobierno de Septimio Severo (193-211 d.C.) y sus sucesores, el siglo III significó el paso de una época de oro a otra de hierro y óxido como rememora el senador Dión Casio ${ }^{3}$. Parte de ese desgaste tuvo que ver con el clima creado por la Peste Antonina. El inicio cronológico de lo que se ha definido como la crisis del siglo III se sitúa en el asesinato de Alejandro Severo en el año 235 d.C. y originó una constante inestabilidad política para el Imperio Romano, que se unió a las consecuencias sociales y económicas arrastradas desde el siglo II.

\section{La peste de Cipriano: los relatos de la sintomatología y efectos}

Sabemos que la Peste de Cipriano tuvo por origen Egipto y se desarrolló entre los años 249 y 270 d.C. en la cuenca del Mediterráneo, difundiéndose hasta ciudades como Roma y Cartago. El gran problema para los historiadores ${ }^{5}$ radica en que mientras la Peste Antonina fue descrita por un médico, Galeno, la Peste de Cipriano fue narrada principalmente por cristianos en una época de persecución, y cargando la descripción con un tono edificantemente religioso. Al respecto, poseemos los textestigos de los hechos, junto con otros relatos un poco más lejanos en el tiempo como el de Zósimo, la Vida de Arnobio y la Historia Augusta ${ }^{6}$.

De los testimonios mencionados anteriormente, el único que revela detalles de la sintomatología es el de Cipriano en su De Mortalitate (De la mortalidad), nombre tos contemporáneos de Cipriano y de Poncio de Cartago, 
sugerente para el impacto general de la epidemia. Entre los detalles de la peste se destacan:

"This trial, that now the bowels, relaxed into a constant flux, discharge the bodily strength; that a fire originated in the marrow ferments into wounds of the fauces; that the intestines are shaken with a continual vomiting; that the eyes are on fire with the injected blood; that in some cases the feet or some parts of the limbs are taken off by the contagion of diseased putrefaction; that from the weakness arising by the maiming and loss of the body, either the gait is enfeebled, or the hearing is obstructed, or the sight darkened;-is profitable as a proof of faith"'.

- Diarrea (fluxum ventrem).

- Decaimiento generalizado y pérdida de energía (corpis vires).

- Dolor abdominal.

- Vómitos.

- Heridas/Dolor de garganta.

- Necrosis de extremidades.

- Ojos enrojecidos.

- Pérdida de audición y visión.

A simple vista los síntomas son variados y los historiadores de la epidemia han luchado por encontrar una respuesta coherente a todos estos. Tradicionalmente se ha creído que los síntomas eran similares a los de la Peste Antonina, asegurando que se trataría de un rebrote de la peste de finales del siglo II. Tanto Harper como Kearns han sostenido, se trataría de una peste distinta, que no sería ni viruela ni peste bubónica. Esta última se podría descartar debido a que lo más llamativo de esta enfermedad son los bubones negros, que han sido largamente descritos en la epidemia del siglo XIV y posteriores, cuestión que en este relato no se encuentra ${ }^{8}$.

Según ambos autores, se trataría de una fiebre hemorrágica viral, cuyos síntomas podrían coincidir con alguna enfermedad similar al Ébola. No obstante, esto es por el momento una suposición considerando el listado de anterior; de todos modos, el sangrado, que es típico en el Ébola, no se encuentra presente en ninguna de las descripciones y también sería un síntoma digno de destacar por su virulencia y violencia.

Otros factores explicativos de por qué podría tratarse de una fiebre hemorrágica viral son de tipo geográfico. En el lugar de origen de la peste, Egipto, existía un clima que permitía la proliferación de mosquitos y roedores, vectores principales de la transmisión de este tipo de enfermedades en la antigüedad ${ }^{7}$. Por otro lado, en Egipto se encontraban las principales redes de interconexión del mar Mediterráneo con el África sub-sahariana, e incluso algunas rutas navales hacia India, haciendo posible la tesis de que el virus originado al interior de África llegara al delta del Nilo y de allí se difundiera al resto del orbis terrarum, el nombre que los romanos daban a su mundo.

Todos los relatos, antiguos y modernos, son concluyentes en señalar la alta mortalidad de la peste de Cipriano. Harper ha estimado que sólo en la ciudad de Alejandría, la segunda urbe más populosa del Imperio Romano con unos 500.000 habitantes, pudo haber muerto una cifra cercana a $60 \%$ de su población, esto es unos 300.000 habitantes (al 7 de julio de 2020, hay 540.572 de muertes por COVID-19 en el mundo ${ }^{9}$ ), nuevamente esto se trata de una mera suposición desde lo cuantitativo, pero desde lo cualitativo nos indica un fuerte descenso demográfico. Al respecto, sabemos que la peste mató a un emperador romano, Claudio Gótico; la reflexión podría trasladarse a nuestro presente con qué pasaría en una potencia mundial con su líder fallecido por COVID-19.

En una época donde no existía conciencia científica del distanciamiento social, la peste se difundió con mayor crudeza en plenos conflictos militares en las fronteras, afectando a romanos y extranjeros por igual. Zósimo recordaba que "todo el Imperio se hallaba conmocionado hasta el punto de ver en peligro su supervivencia, cuando una peste de magnitud no igualada nunca antes cayó sobre las ciudades e hizo que las desgracias debidas a los bárbaros pareciesen más llevaderas" ${ }^{10}$; el relato de la memoria histórica es interesante, puesto que la Peste Antonina había afectado recientemente a una o dos generaciones anteriores.

Pensemos también en las vías de contacto. Hablamos de un Imperio Romano unificado administrativamente, con una población estimada en unos 40 a 60 millones de habitantes, donde la libertad de movimiento era algo fundamental y donde las rutas comerciales se extendían desde la actual Inglaterra en el norte, hasta el Éufrates en oriente; desde los helados Rhin y Danubio en el septentrión hasta las ardientes arenas del Sahara en el sur, un Imperio sin barreras internas, salvo las limitaciones propias de los medios de transporte. En ese espacio geográfico físico y humano la propagación de la pestilencia fue fácil y total, del mismo modo que hoy ocurre con el COVID-19, con la diferencia fundamental de los avances científicos en salud (Figura 1).

\section{Los impactos de la Peste de Cipriano}

La Peste de Cipriano adquirió connotaciones fatalistas y apocalípticas. Desde un punto de vista demográfico, sabemos que tuvo una alta tasa de mortalidad, algunos aseguran que mayor que la de la Peste Antonina, habiendo estimado Harper una mortalidad de entre 10 y $20 \%{ }^{11}$. La 
Historia Augusta, escrita en el primer tercio del siglo IV, rememoraba que en tiempos del emperador Galieno (253-268 d.C.) "había surgido una epidemia de peste tan grande en Roma y en las ciudades griegas, que en un solo día murieron por la misma enfermedad cinco mil hombres. Cuando la fortuna se mostraba cruel, mientras en un sitio un terremoto, en otro las hendiduras del suelo $\mathrm{y}$ en todas partes la peste devastaba el mundo romano"12. La Historia Augusta atribuye a la peste cinco mil muertos por día y circunscribe la peste al área oriental del Imperio y la ciudad de Roma. Relacionado con lo anterior, Zósimo menciona que varias ciudades quedaron desiertas, que Macedonia y Tracia quedaron despobladas, al punto que se permitió que enemigos de Roma se establecieran en esas tierras como campesinos ante la ausencia de mano de obra, medidas que ya se habían utilizado con la Peste Antonina ${ }^{10}$.

Poncio de Cartago, un diácono del obispo Cipriano añadió en su descripción el impacto mental de la peste, remarcando que en su memoria: "No one trembled at there membrance of a similar event" "13 algo que Zósimo también había enunciado. La peste, según su narración, produjo destrucción, temor en la población, y psicosis, pues la gente evitaba tomar contacto entre sí debido a una alta mortandad; sin quererlo, la humanidad comprendía el distanciamiento social como una medida para evitar la difusión de la pandemia.

Pero mientras en la Peste Antonina el gran impacto fue de orden económico al alterar toda la estructura productiva y hacer más pesadas las cargas de las guerras que se luchaban, en la Peste de Cipriano el impacto también fue global y sobre todo, en la estructura ideológico-religiosa. El estado romano, pagano, optó por enfrentar la pandemia pidiendo ayuda a sus dioses. En la imagen siguiente se puede observar al emperador Treboniano Galo difundiendo la leyenda salus (salud) como medida de protección divina (Figura 2).

La peste se tradujo en una fuerte querella religiosa, los paganos culpaban a los cristianos y viceversa, de ser los instigadores de la peste. Los observadores cristianos insistieron que la peste era un castigo para los judíos y paganos por sus males provocados por perseguir al cristianismo, "Pero las pestes, dicen mis oponentes, y las sequías, guerras, hambrunas, langostas, ratones y granizo, y otras cosas hirientes, por las cuales la propiedad de los hombres es atacada, los dioses nos traen, indignados como están por sus malas acciones. y por tus transgresiones"14. Fue un discurso atractivo, muchos paganos miraron al cristianismo como una tabla de salvación, la diosa romana salus, a pesar de hacerle sacrificios, de buscar contentarla mediante la piedad religiosa, parecía no responder, ¿los dioses habían abandonado al Estado romano y mostraban su desprecio por medio de la pandemia? Muchos creyeron que sí, y el

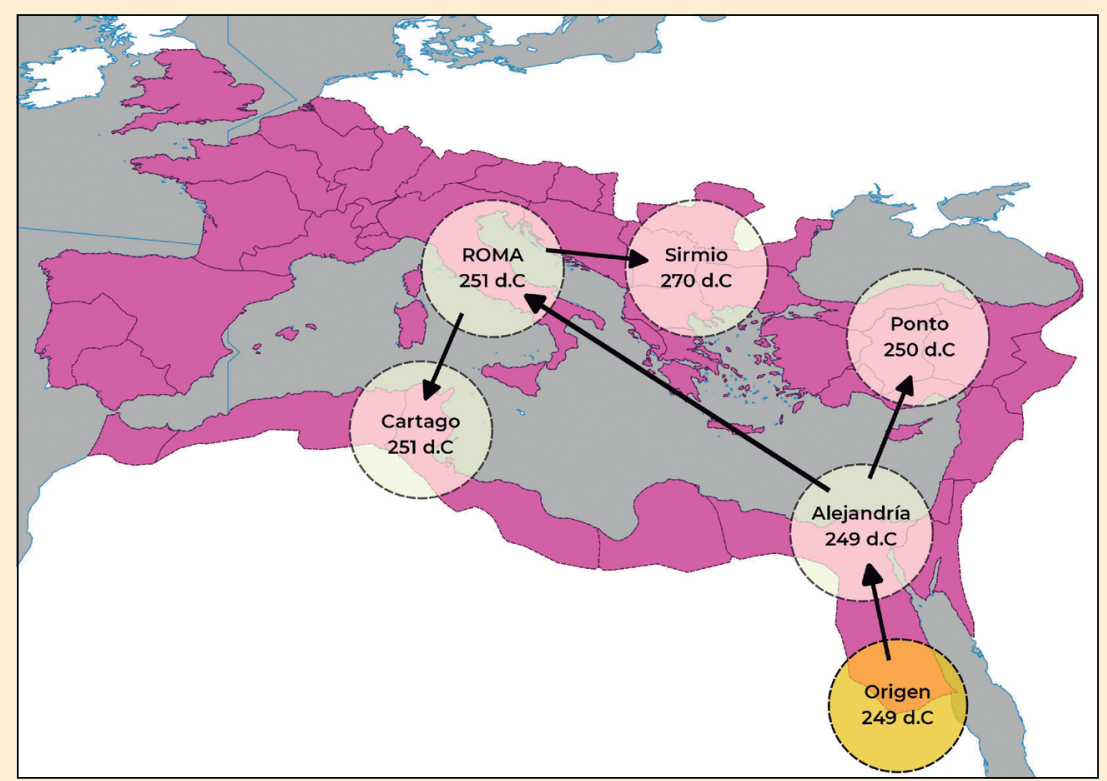

Figura 1. Mapa de difusión de la Peste de Cipriano. Fuente: Creación propia.

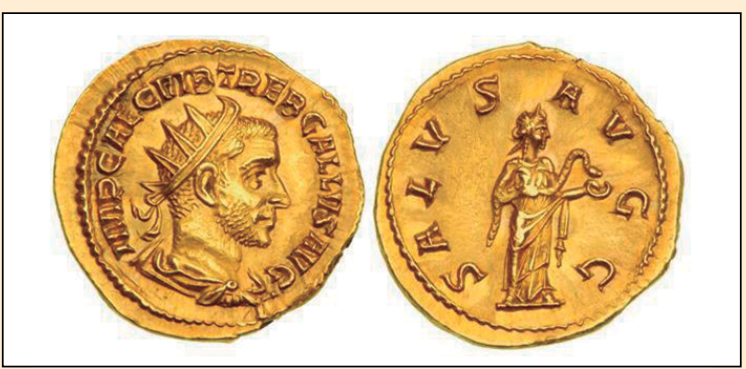

Figura 2. Salus Augusti. Moneda de Treboniano Galo (251-253). Fuente: http://www.wildwinds.com/coins/ric/treboJnianus_gallus/ RIC_0013.jpg.

cristianismo se transformó en una religión masiva, que, aunque prohibida, creció en feligresía.

La comentada Peste Antonina a finales del siglo II, recordemos, tuvo efectos similares. Sus consecuencias estuvieron presentes durante todo el siglo III, su carácter global, afectando la estructura política, social, económica y mental tuvo un efecto imperecedero, el Imperio se vio obligado a cambiar. Esos cambios estaban en proceso cuando apareció la pandemia de la Peste de Cipriano, pero el impacto fue igual de global, tanto en la escala como en diferentes dimensiones. Pasada la crisis, el Imperio ya no recuperaría jamás su fisonomía histórica, la edad antigua quedaba atrás y tañían las campanas de la edad media, marcada por el surgimiento de una nueva fe que podía satisfacer la necesidad de una salvación espiritual: el cristianismo. 


\begin{tabular}{cll}
\hline \multicolumn{2}{c}{ Tabla $\mathbf{1}$. Ciclo de pestes entre el siglo II y el siglo III } & \\
\hline Fecha & Nombre & Mortalidad estimada \\
$165-180$ & Peste Antonina & $5-15 \%($ Sáez, 2016) \\
& & $10-20 \%($ Harper, 2016) \\
$180-193$ & Peste Antonina (oleadas menores) & $5-15 \%$ \\
$218-222$ & Peste & $\mathrm{N} / \mathrm{S}$ \\
$253-260$ & Peste de Cipriano & $15-25 \%($ Harper,2016) \\
& & Est. $60 \%$ muertos en áreas urbanas, 5.000 muertos día \\
\hline
\end{tabular}

\section{Conclusiones: De la Peste Antonina a la Peste de Cipriano}

En un lapso de 100 años, el Imperio Romano sufrió, de acuerdo a la documentación, grandes brotes de pestilencia, profusamente difundidos en las regiones más ricas de un Imperio, que podría considerarse como global (Tabla 1). En dos o tres cohortes demográficas se produjo un impacto brutal en la estructura social y económica, pauperizando el trabajo campesino y del artesanado urbano, que prácticamente perdió la movilidad social y se encontró adscrito vitaliciamente a un oficio. Al contrario de nuestras pestes actuales, cuya tasa de mortalidad es menor debido al impacto de los avances científicos, en el Imperio Romano hubo empleos que no pudieron ser cubiertos.

La Peste Antonina, que se desarrolló a fines del siglo II, puede ser considerada global por las implicancias y alcances que tuvo en el Imperio Romano. En el inestable siglo III, la Peste Cipriana produjo resultados aún peores por la debilidad del Estado romano, a pesar de ser una pandemia en términos de alcances bastante similar. No hay claridad si la Peste Cipriana sería un rebrote de la Peste Antonina, o más bien de una fiebre viral como el Ébola; es difícil saberlo y aventurarse a dar una respuesta, es la arqueología quien podría proporcionarnos nuevas luces al respecto. Mientras la principal y más importante consecuencia de la Peste Antonina fue la alteración de la estructura productiva con efectos importantes en la economía del imperio, la consecuencia más importante de la Peste Cipriana sería en el aspecto ideológico-religioso.

En clave militar las bajas por enfermedades en un contexto donde los hombres hábiles para el servicio eran escasos, produjo un impacto al no disponer de tropas para defender las fronteras. Los pueblos del norte, migrando por la presión climática, presionaron las fronteras y el ejército no fue capaz de impedirlo; este proceso de invasiones junto con la emergencia del cristianismo como fe mayoritaria en la sociedad son claves para comprender el fin del mundo antiguo. En ambos casos, las pestes y enfermedades han sido infra-valoradas como fenómeno explicativo de esos procesos.
¿Qué lecciones nos deja para hoy? En primer lugar, la valoración de las ciencias médicas en el tratamiento racional de las enfermedades. En segundo lugar, desde un punto histórico, que la humanidad desde sus propios orígenes ha debido enfrentarse a estas pandemias, por lo que es lícito preguntarse ¿Qué es lo normal? ¿La ausencia o existencia de pandemias? Lo que el mundo vive hoy en 2020 no es muy diferente de lo que hace 1.700 años atrás tuvo que afrontar el Imperio Romano y lo que posteriormente la humanidad enfrentaría; la gran diferencia está en cómo la conciencia, la razón y la ciencia nos permiten tomar decisiones correctas para el futuro.

Agradecimientos. Se agradece al Proyecto Fondecyt de Iniciación $\mathrm{N}^{\circ}$ 11180219, titulado: "La Pax Antonina: ideología militar, política exterior y gran estrategia del Imperio Romano en el siglo de los antoninos." Académico responsable, Andrés Sáez Geoffroy.

\section{Referencias bibliográficas}

1.- OMS. ¿Qué es una pandemia?, https://www.who.int/csr/ disease/swineflu/frequently_asked_questions/pandemic/es/. (Acceso el 26 de mayo de 2020).

2.- Sáez A. La peste Antonina: una peste global en el siglo II d.C. Rev Chilena Infectol 2016; 33: 218-221. http://dx.doi. org/10.4067/S0716-10182016000200011.

3.- Cassius Dio. Roman History, trad. Earnest Cary, 1th ed. Cambridge: Harvard University Press; 1927.

4.- Bancalari A. Orden Romano e Imperio Global, la romanización de Augusto a Caracalla. 1 ed. Santiago de Chile: Editorial Universitaria, 2007.

5.- Harper K. The fate of Rome: climate, disease, and the end of an empire, 1th ed. Princeton: Princeton University Press; 2017.

6.- Harper K. People, Plagues, and Prices in the Roman World: The Evidence from Egypt. J Economic History 2016; 76: 803-39. doi: https://doi.org/10.1017/S0022050716000826.

7.- Cipriano, Chapter: de Mortalitate. Roberts A, Donaldson J, editors. The ante-nicene fathers. Translations of the writings of the fathers down to a.d 325.1 ed. New York: Charles Scribner's sons; 1919.

8.- Kearns A. Plague in a Crisis: Differential Diagnosis 
of the Cyprian Plague and its Effects on The Roman Empire in the Third Century CE. Electronic Thesis of the University of Arizona; 2018. https://repository.arizona.edu/ handle/10150/628104.

9.- John Hopkins University, Coronavirus Resource Center, https://coronavirus.jhu.edu/map.html (Acceso el 7 de julio de 2020).

10.- Zósimo, Historia Secreta. 1ed. Madrid: Editorial Gredos; 1992.

11.- Harper K. Pandemics and Passages to Late Antiquity: Rethinking the Plague of c. 249-70 described by Cyprian.
J Roman Archaeol 2015; 28: 223-60. doi: https://doi. org/10.1017/S1047759415002470.

12.- Cascón A, Picón V. Historia Augusta. Akal, 1era Edición, Madrid; 1989.

13.- Pontius. Chapter: The Life and passion of Cyprian. Roberts A, Donaldson J, editors. The ante-nicene fathers. Translations of the writings of the fathers down to a.d 325.1 ed. New York: Charles Scribner's sons; 1919

14.- Arnobius of Sicca, Against the Heathen link: https://www. newadvent.org/fathers/0631.htm. Acceso el 26 de mayo de 2020.

\section{SARS - COV - DOS}

Mido más de cien veces menos

Que un mísero milímetro,

Nadie me descubre

A simple vista,

Solo tengo apenas

Quince genes

En una sola cadena

De ácido ribonucleico.

Y con ellos me basta

Para confinarlos a todos

Y tener hoy día

Al mundo de rodillas.

Salto del animal

Al mundo humano

Y no me ven,

pero le temen

A mi fuerza.

Soy el actor de la pandemia

Y los pongo a todos

Bien enfrente

Del temor y de la muerte,

Para que reflexione

Esta raza humana

Y deje de lado

su soberbia prepotente.

No hay otro mensaje...

Soy el virus emergente

Nunca imaginado.

SARS-CoV-Dos, COVID-19

O simplemente coronavirus

Esas son mis firmas.

\section{Heriberto Fernández}

Instituto de Microbiología Clínica.

Universidad Austral de Chile 